\title{
Factors Influencing Fertility Intentions of Newlyweds in South Korea: Focus on Demographics, Socioeconomics, Housing Situation, Residential Satisfaction, and Housing Expectation
}

\author{
Seran Jeon $\mathbb{1}$, Myounghoon Lee and Seiyong Kim * \\ Department of Architecture, Korea University, Anam-dong, Seongbuk-gu, Seoul 02841, Korea; \\ seran217@hanmail.net (S.J.); 83myul@hanmail.net (M.L.) \\ * Correspondence: kksy@korea.ac.kr; Tel.: +82-2-3290-3914
}

Citation: Jeon, S.; Lee, M.; Kim, S. Factors Influencing Fertility Intentions of Newlyweds in South Korea: Focus on Demographics, Socioeconomics, Housing Situation, Residential Satisfaction, and Housing Expectation. Sustainability 2021, 13, 1534. https://doi.org/10.3390/su 13031534

Academic Editor: Colin A. Jones

Received: 13 January 2021

Accepted: 27 January 2021

Published: 1 February 2021

Publisher's Note: MDPI stays neutral with regard to jurisdictional claims in published maps and institutional affiliations.

Copyright: (c) 2021 by the authors. Licensee MDPI, Basel, Switzerland. This article is an open access article distributed under the terms and conditions of the Creative Commons Attribution (CC BY) license (https:/ / creativecommons.org/licenses/by/ $4.0 /)$.

\begin{abstract}
Since 2001, South Korea has experienced sustained lowest-low fertility. This phenomenon has persisted despite the implementation of several social policies aimed at increasing fertility rates. The purpose of this study was to quantitatively analyze the demographics, socioeconomics, housing situation, residential environment, and housing expectation of newlyweds in terms of their fertility intentions in South Korea (within 5 years of marriage) in order to help the development of more effective housing policies. We extracted the factors on the basis of fertility theories and previous related studies and identified differential characteristics of the impact on fertility intentions for the first and for additional child(ren). The results show that fertility intention was higher in nonmetropolitan and rental households. There was also a significant relationship between the anticipated period of a home purchase and fertility intention. In particular, for one-child families, the second child fertility intention was significantly affected. In conclusion, we quantitatively confirmed various factors that significantly impact the fertility plans of newlyweds. We suggest that the government implements housing policies on the basis of economic stability, the number of children, and the residential environment of newlywed couples.
\end{abstract}

Keywords: newlyweds; fertility intention; demographics; socioeconomics; housing situation; residential satisfaction; housing expectation; housing policy

\section{Introduction}

In 2001, South Korea recorded a total fertility rate of 1.30 , becoming the lowest-low fertility society, with this social phenomenon persisting to this day-the total fertility rate was 0.98 in 2018, 0.92 in 2019, and is expected to drop to 0.86 by 2021 [1]. In response, the government implemented several policies to address these low fertility issues, such as the "Third Master Plan of Low Fertility Aged Society" and "Housing Special-Provision Policy". However, most of these policies focused on multi-child families with three or more children, while fertility support for households with less than three children has been excluded.

According to the 2015 Newlyweds Panel Analysis of Housing Conditions by the Ministry of Land, Infrastructure and Transport, $16.2 \%$ of newlyweds currently do not have children, with more than $74.9 \%$ of households delaying their fertility plans due to difficulties in their careers, the burden of parenting, and economic circumstances [2]. Moreover, the average number of children of newlyweds is 1.16. Although the birth of a first child after marriage is most common for newlyweds, considering that newlyweds (defined as within five years of marriage) are the population group having children, it is necessary to implement targeted residential environment and housing policies to increase the fertility rate of newlyweds [3].

Recently, the residential environment has experienced rapid changes due to alterations in the social environment. The residential patterns of housing type, housing expenses, 
housing tenure type, and residential period have had a significant influence on marriage and fertility $[4,5]$. Moreover, socio-cultural problems such as insufficient childcare support, parenting expenses, and marriage delays have been suggested as the cause of lowest-low fertility. Among these causes, housing issues are a critical factor directly contributing to the low fertility problem in South Korea.

Previous studies analyzed social, economic, and residential behavioral impacts on the fertility intention of married women to prepare measures counteracting low birthrates. Chun examined the cause of low fertility and the current state of housing policies related to fertility support and emphasized a necessity of the compatible residential setting for work and childcare, housing provision to support childcare and housework, social interest, and a shifted perception in the direction of residential policy for revitalizing the fertility rate [5]. In addition, Chun proposed that residential policies are the basis for supporting childbirth by empirically identifying the effects of housing policies on fertility support and the influences of residential charges on the birth rate [5]. Jeong critically reviewed the contents and problems of counter plans against the low fertility and highlighted the importance of political promotion to create an advantageous setting for childbirth via the reduction of childcare responsibility, the expansion of public childcare services, and the initiation of parental leaves [6]. Seo suggested age, parental value, the burden of costs, and career responsibility as the principal factors influencing the fertility intention of married women, i.e., the number of planned children [7]. Moreover, Seo underlined the significance of selective approaches across the number of born children, in contrast to a comprehensive approach, in order to deal with the issue of low fertility, as the beneficial capacity and child value were found to vary when women with a child plan to have additional children [7]. Jeong noticed the need for policies to alleviate the burden of delivering and parenting a child and the necessity of plans to promote the family support system to aid parenting, as suggested by the fertility age for the first child, educational levels, health status, and marriage satisfaction as the major influencing factors for the second childbirth [8]. Kang highlighted the necessity to create an overall environment that can reduce education and child-rearing costs, rather than temporary support, on the basis of a survey revealing that factors for the intention of the subsequent fertility were age, academic background, income, family make-up, and the number and gender of children [9].

These studies have crucial implications not only from an academic perspective but also from a political perspective, for what kind of and how much housing will affect marriage or fertility. However, housing itself has an impact, i.e., via residential patterns, rather than influencing marriage and fertility. Park et al. analyzed the relationship between housing and fertility [10]. Describing housing stability and parenting affinity as positive influencing factors on the fertility intention, Park states that facilities related to childbirth and parenting should meet the aspect of life convenience and increase the overall birth rate because these factors directly impact the fertility rate. Lee highlighted that the impact of housing on marriage and fertility differs depending on house ownership, housing type, residential period, housing purchase cost, and housing size, and that, thereby, differentiated housing policies should be approached by the types of housing [11]. Mulder and Billari investigated the association between fertility rates and homeownership regimes in Western countries [12]. They analyzed four types of homeownership regimes in terms of the owner-occupied housing and mortgage accessibility, and argued that countries with homeownership regimes with a high share of owners and low access to mortgages have the lowest fertility rates [12]. Masanja et al. studied factors driving the decrease in fertility rates in urban and rural areas in Tanzania [13]. The authors suggested the need for appropriate government policies and programs to match social changes that affect the fertility rate, such as small family sizes, improving the level of children's education, and a change in the social status of women. Vignoli et al. investigated the relationship between the fertility rate and the economic situation [14]. They found that the psychological stability of residents in the current residential environment is an important factor in fertility intentions. In addition, they argued that social and economic policies should be supported to increase the fertility 
rate because employment security and economic conditions are related to a sense of stability in the residential environment. Sági and Lentner studied Hungarian pro-birth policies and reported a policy gap in housing subsidies [15]. The authors evaluated family policy interventions such as housing support, tax allowances, and other child-raising benefits and concluded that an optimal mix of family policy incentives could maintain sustainable level of birth rate levels, but not necessarily increase them.

Previous studies exploring the factors influencing fertility intention and childbirth planning have focused on demographic factors such as wife's age, income, education level, and family composition [8,9]; socioeconomic factors such as income and childcare expenses [5-7,13]; and housing factors such as housing type, size of housing, housing satisfaction, and housing costs $[4,10-12,14,15]$. In addition, the studies explored parental leave, employment stability, childcare-friendly environment, social awareness trends, and economic activities of women $[5,6,10,13]$. Table 1 summarizes the outcomes of prior studies on fertility and its effects on demographics, socioeconomics, and housing. Most of these previous studies analyzed influencing factors on the fertility intention on the basis of ordinary families, although the main subjects of pregnancy planning and childbirth.

Table 1. Previous studies on fertility and the influences of demographics, socioeconomics, and housing.

\begin{tabular}{|c|c|c|}
\hline Major Study Focus & Authors & Influences \\
\hline \multirow{2}{*}{ Demographics } & Jeong [8] & Educational levels and period, healthy status, marriage satisfaction \\
\hline & Kang [9] & $\begin{array}{l}\text { Age, educational background, income, family composition, number of } \\
\text { children, the gender of children }\end{array}$ \\
\hline \multirow{4}{*}{ Socioeconomics } & Chun [5] & $\begin{array}{l}\text { Income, values of marriage and family, women's economic circle, parenting } \\
\text { expenses, housing expenses }\end{array}$ \\
\hline & Jeong [6] & $\begin{array}{l}\text { Reduction of childcare responsibility, expansion of public childcare services, } \\
\text { activation of parental leave }\end{array}$ \\
\hline & Seo [7] & $\begin{array}{l}\text { Women's age, income, child value, parental value, charge of expenses, the } \\
\text { approval rating of policy, beneficial capability }\end{array}$ \\
\hline & Masanja et al. [13] & Women's empowerment, social transformation, differentials in education \\
\hline \multirow{6}{*}{ Housing } & Lee [4] & $\begin{array}{l}\text { Housing tenure, housing type, extent of parental support for housing } \\
\text { purchase, housing size, residential period }\end{array}$ \\
\hline & Park et al. [10] & $\begin{array}{l}\text { Satisfaction in the community environment, residential satisfaction, stability, } \\
\text { life convenience, childcare-friendly environment }\end{array}$ \\
\hline & Lee [11] & $\begin{array}{l}\text { House ownership, housing type, residential period, housing purchase cost, } \\
\text { housing size }\end{array}$ \\
\hline & Mulder and Billari [12] & Housing purchase cost, housing ownership \\
\hline & Vignoli et al. [14] & The psychological stability in the current residential environment \\
\hline & Sági and Lentner [15] & $\begin{array}{l}\text { Housing prices, regulatory gap in the housing market, family } \\
\text { policy incentive }\end{array}$ \\
\hline
\end{tabular}

To overcome the limitations of previous studies, we first based our study on the influences commonly emphasized in fertility theories and previous studies. Available variables were extracted; classified into the characteristics of demographic, economic, and residential environments; and used for analysis. Second, factors affecting the fertility intention and plans of newlyweds, the main subjects of counter plans against low fertility, not ordinary households, were considered on the basis of national survey data. Third, to deal with low fertility issues, it is more important to selectively approach the number of born children rather than to comprehensively approach the fertility intention. On the basis of these assumptions, we identified whether there are differentiated characteristics between the influences on the period of the initial childbirth planning and the affecting factors on the plans for the first and second child. 
The remainder of this study is structured as follows. Section 2 presents the research method, the selected model for empirical analysis, selected variables and the data analysis, and a descriptive analysis of the variables. In Section 3, on the basis of the influences revealed in prior fertility theories and studies, we extract and analyze the characteristics of demographics, socioeconomics, housing situation, residential environment, and housing expectation as derived from the Newlyweds Panel Analysis of Housing Conditions dataset. In Section 4, the significance of this study and future research directions are highlighted.

\section{Materials and Methods}

Publicly available microdata from the 2015 Newlyweds Panel Analysis of Housing Conditions released by the Ministry of Land, Infrastructure and Transport (https: / / mdis. kostat.go.kr) was used in this study [1,2]. In total, data on 2702 first-married couples within 5 years of marriage were selected for the analysis, whose marriages were reported from 1 January 2010 to 31 December 2014. Factors, such as the characteristics of demographics, socioeconomics, housing situation, residential satisfaction, and housing expectation were extracted on the basis of influences revealed in prior fertility theories and studies [3-6,14].

The demographic characteristics were categorized by the age of the wife, the duration of the marriage, and the residential region (metropolitan/non-metropolitan). The Republic of Korea is divided into 5 districts as follows: Seoul area (Seoul Metropolitan City), Gyeongin area (Incheon, Gyeonggi-do, Gangwon-do), Chungcheong area (Daejeon, Sejong Special Self-Governing City, Chungcheongnam-do, Chungcheongbuk-do), Jeolla area (Gwangju, Jeollabuk-do, Jeollanam-do, Jeju-do), and Gyeongsang area (Daegu, Ulsan, Busan, Gyeongsangbuk-do, Gyeongsangnam-do). The metropolitan region includes Seoul city, Incheon city, and Gyeonggi province. The wife's age value was generated by converting the date of birth. Economic characteristics were defined as income, mortgage (monthly expenses), and dual-income status. Pre-tax gross annual salary statements were used for income, and mortgages were applied to the analysis on the basis of mortgage statement as an average monthly expense.

The residential attributes were defined as housing ownership, rental status, and apartments or non-apartments. Residential satisfaction consisted of the satisfaction of the housing setting and environment of residential area. The housing setting satisfaction was based on the house location, housing condition, and management cost. The satisfaction of the environment of residential area was surveyed on satisfaction with local safety, local markets, transportation, neighboring nature, and child-friendly environment. The value of residential environment was calculated by averaging the satisfaction of housing setting and environment of residential area. The newlyweds' expected years of house purchase was classified as follows: less than 1 year, 1 to 3 years, 3 to 5 years, 5 to 10 years, more than 10 years, impossible, and unknown. Further residential circumstances were applied for the analysis using statements of the anticipated period for housing purchase.

We set up model 1, model 2, and model 3 to analyze factors affecting the fertility intention of newlyweds. Model 1 analyzed whether newlyweds had the intention to plan their fertility in particular situations, regardless of whether they have a child. Via model 2, the factors influencing the fertility intention for the first child were identified, and model 3 was applied to analyze the factors influencing additional childbirth, on the basis of first-married couples with one child only.

We used a binomial logistic regression for our statistical analysis. Logistic regression analysis was developed to alleviate the challenge of calculation, which is a disadvantage of the Probit model, with logistic regression being a model of selected probability assuming that the probabilistic utility is an independent distribution with a Weibull distribution. The purpose and procedure of the analysis are similar to linear regression analysis but differ in that ostensible-typed variables are applied as dependent variables. Logistic regression analysis utilizes odds, a ratio between the probability of occurrence and the probability of non-occurrence. The corresponding formula is expressed as Odds $=p /(1-p)$. The 
concept of odds cannot be used for the general regression analysis with values between 0 and 1 .

The concept of odds has 2 problems: the first is that it does not have negative (-) values, and the second is that the relationship among probabilities reveals an asymmetry around 1. As a method to solve these problems, natural logs are assigned to the values of odds, which is called logit. On the condition of a given explanatory variable, if the S-shape of a logistic function with a maximum value of 1 and a minimum value of 0 , which represents the probabilities that a particular choice occurs or not, is converted to logit, it appears linearly. The formula is expressed as follows:

$$
\begin{gathered}
\text { Odds }=\frac{\mathrm{p}}{1-\mathrm{p}}=\exp \left[\alpha+\mathrm{B}_{1} \mathrm{X}_{1}+\mathrm{B}_{2} \mathrm{X}_{2}+\cdots+\mathrm{B}_{\mathrm{p}} \mathrm{X}_{\mathrm{p}}\right] \\
\ln \left(\frac{\mathrm{p}}{1-\mathrm{p}}\right)=\alpha+\mathrm{B}_{1} \mathrm{X}_{1}+\mathrm{B}_{2} \mathrm{X}_{2}+\cdots+\mathrm{B}_{\mathrm{p}} \mathrm{X}_{\mathrm{p}}
\end{gathered}
$$

The concept of the odds ratio is used in the interpretation of the logistic regression analysis. The odds ratio refers to a change as $X_{i}$ increases by a unit, given that the explanatory variable is constant. The formula is expressed as follows:

$$
\text { Odds Ratio }=\frac{\operatorname{Exp}\left(a+B_{1} X_{1}+\cdots+B_{i}\left(X_{i}+1\right)+\cdots+B_{p} X_{p}\right)}{\operatorname{Exp}\left(a+B_{1} X_{1}+\cdots+B_{i} X_{i}+\cdots+B_{p} X_{p}\right)}=\operatorname{Exp}\left(B_{i}\right)
$$

If the odds ratio is less than 1 , the explanatory variable $X_{i}$ has a negative (-) impact on the dependent variables, and if the odds ratio is larger than $1, X_{i}$ has a positive $(+)$ influence. All analyses were performed using IBM SPSS Statistics ver. 22.0 (IBM Corp., Armonk, NY, USA).

\section{Results}

\subsection{Descriptive Analysis}

The descriptive analysis results of the 2015 Newlyweds Panel Analysis of Housing Conditions are shown in Table 2. The average age of the wives of the newlyweds was 32.24 years. The average annual income for households was 4810.5 million won (approximately EUR 38,262) for households, and the average monthly mortgage was 28.5 million won (approximately EUR 226). Note that the average basic rate of exchange in 2015 was used for the currency conversion (Korean Statistical Information Service, https:/ / kosis.kr).

According to the characteristics of newlyweds, the proportion of households living in a rental relationship (70.6\%) during the study period was higher than that of households owning their home $(29.4 \%)$, and the proportion of households living in an apartment $(61.7 \%)$ was higher than that of households living in a non-apartment (38.3\%). Although this can be interpreted as newlyweds tending to prefer to live in an apartment, it is regarded as due to the surveys being conducted in urban areas in which many of the participants resided under the identified characteristics of newlyweds [2].

\subsection{Factors Influencing Fertility Intention of Newlyweds}

Whether newlyweds have fertility intentions in particular situations, regardless of already having children, was analyzed using model 1 (Table 3). The results show that during the study period, the fertility plan was correlated with the age of the wife and marriage duration. Non-metropolitan residents had a 1.369 times higher fertility plan than residents in metropolitan areas. This can be interpreted as being a result of economic factors, such as high housing costs, child support expenses, education expenses, and income instability, despite the relatively large proportion of young people in their 20s and 30s living in metropolitan areas [10,16-18]. 
Table 2. Descriptive analysis.

\begin{tabular}{|c|c|c|c|c|c|c|c|c|c|}
\hline \multicolumn{2}{|c|}{ Variable Type } & \multicolumn{2}{|c|}{ Variable Name } & \multirow{2}{*}{$\begin{array}{c}\text { Frequency } \\
2114 \\
\end{array}$} & \multirow{2}{*}{\begin{tabular}{|c} 
Proportion (\%) \\
21.8 \\
\end{tabular}} & \multirow{2}{*}{$\begin{array}{c}\text { Min } \\
-\end{array}$} & \multirow{2}{*}{$\begin{array}{c}\text { Max } \\
-\end{array}$} & \multirow{2}{*}{$\begin{array}{c}\text { Average } \\
-\end{array}$} & \multirow{2}{*}{$\begin{array}{c}\text { Standard } \\
\text { Deviation } \\
-\end{array}$} \\
\hline \multirow{4}{*}{\multicolumn{2}{|c|}{ Dependent variables }} & \multirow{2}{*}{ Presence of children } & Yes & & & & & & \\
\hline & & & No & 588 & 72.2 & - & - & - & - \\
\hline & & \multirow{2}{*}{ Presence of a fertility plan } & Yes & 1889 & 69.9 & - & - & - & - \\
\hline & & & No & 813 & 30.1 & - & - & - & - \\
\hline \multirow{15}{*}{$\begin{array}{l}\text { Independent } \\
\text { variables }\end{array}$} & \multirow{4}{*}{ Demographics } & \multicolumn{2}{|c|}{ Age of wife (years) } & - & - & 19 & 49 & 32.24 & 4.03 \\
\hline & & Marriage period & 3rd to 5 th year & 1335 & 49.4 & - & - & - & - \\
\hline & & \multirow{2}{*}{ Residential region } & Metropolitan & 1519 & 56.2 & - & - & - & - \\
\hline & & & Non-metropolitan & 1183 & 43.8 & - & - & - & - \\
\hline & \multirow{3}{*}{ Socioeconomics } & \multicolumn{2}{|c|}{ Annual income (pre-tax/million won) } & - & - & 0 & 28,000 & 4810.5 & 2064.9 \\
\hline & & \multicolumn{2}{|c|}{ Mortgage (monthly /million won) } & - & - & 0 & 650 & 28.5 & 46.8 \\
\hline & & Dual-income status & Single & 1169 & 43.3 & - & - & - & - \\
\hline & \multirow{4}{*}{$\begin{array}{l}\text { Housing } \\
\text { situation }\end{array}$} & \multirow{2}{*}{ Ownership status } & Owned & 795 & 29.4 & - & - & - & - \\
\hline & & & Rent & 1907 & 70.6 & - & - & - & - \\
\hline & & \multirow{2}{*}{ Residential type } & Apartment & 1666 & 61.7 & - & - & - & - \\
\hline & & & Non-apartment & 1036 & 38.3 & - & - & - & - \\
\hline & \multirow{3}{*}{$\begin{array}{l}\text { Residential } \\
\text { satisfaction }\end{array}$} & \multicolumn{2}{|c|}{$\begin{array}{l}\text { Residential environment (average of housing setting } \\
\text { and environment of residential area) }\end{array}$} & - & - & 1 & 4 & 2.94 & 0.53 \\
\hline & & \multicolumn{2}{|c|}{ Housing setting } & - & - & 1 & 4 & 2.93 & 0.57 \\
\hline & & \multicolumn{2}{|c|}{ Environment of residential area } & - & - & 1 & 4 & 2.91 & 0.56 \\
\hline & $\begin{array}{l}\text { Housing } \\
\text { expectation }\end{array}$ & \multicolumn{2}{|c|}{ Anticipated years of housing purchase } & - & - & 0 & 11.7 & 8.6 & 50.15 \\
\hline
\end{tabular}


Table 3. Factors influencing fertility intention of newlyweds (model 1).

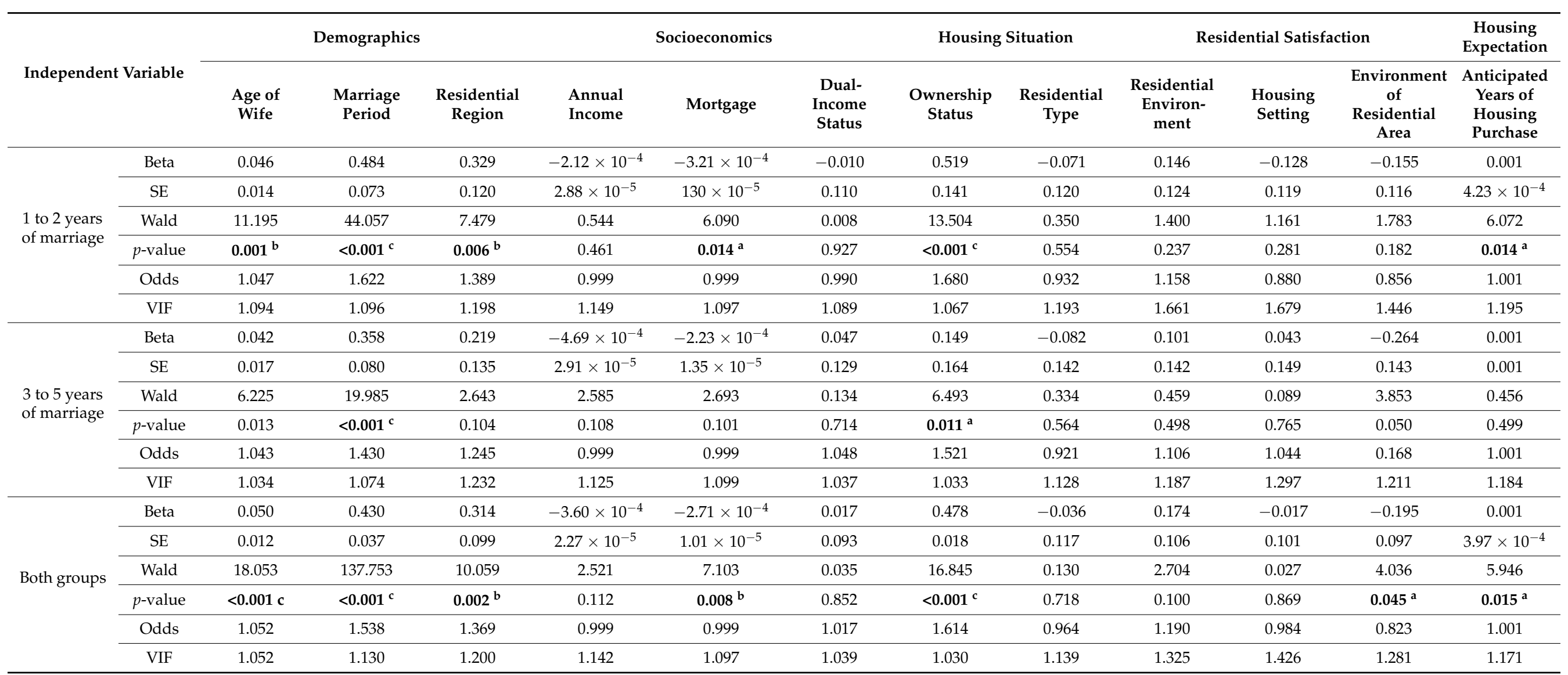

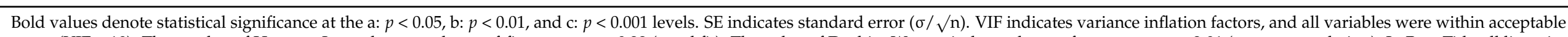

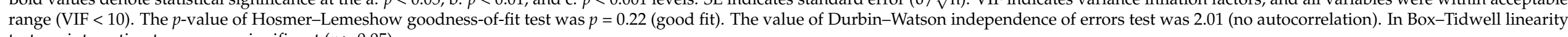
test, no interaction terms were significant $(p>0.05)$. 
In terms of housing characteristics, the fertility plans of newlyweds living in rental households were 1.614 times higher than those of newlyweds living in their own homes. More specifically, newlyweds living in rental households had fertility intentions 1.680 times (1-2 years of marriage) and 1.521 times (3-5 years of marriage) higher than those who owned their home. Although this is inconsistent with the general perception that renting would more negatively impact fertility than owning a home, these results are consistent with the data (24.4\% of owners, $43.9 \%$ of renters) of the 2015 Newlyweds Panel Analysis of Housing Conditions, which examined whether newlyweds planned on having a child according to housing tenure type $[2,16]$.

Our analysis shows that households with a short anticipatory period for home purchases and/or those that are satisfied with their residential area are more likely to have children. This can be explained by the fact that housing stability for raising children is closely related to fertility rates.

\subsection{Factors Influencing Fertility Intention of Newlyweds for the First Child}

Model 2 shows the factors affecting the fertility intention of the first child (Table 4). Demographic characteristics have shown that the age of the wife and the marriage duration have a significant effect on the birth of their first child. This is in line with results of previous studies, which have shown that ordinary households, including newlyweds, have lower birthrates and newlyweds are older on average when they get married $[2,18]$.

As shown in Table 4, the fertility plans of non-metropolitan residents were 1.483 times higher than of those living in metropolitan areas. Regardless of marriage duration (1-2 and 3-5 years of marriage), plans for the first child depended on the housing characteristics, with rental residents having 1.529 times higher birth plans than homeowners. Non-apartment residents had 1.623 times higher birth plans than apartment residents.

\subsection{Factors Influencing Fertility Intention of Newlyweds for Additional Children}

The factors affecting the fertility plans for additional children of newlyweds with a child were analyzed using model 3 (Table 5). Although there were differences in the fertility plans for an additional child in terms of the level of income of the newlyweds, specific patterns were unclear. In the past, an increase in the level of income was generally recognized to increase the fertility rate due to the younger age of the couple getting married and of the wife at childbirth. However, the phenomenon of giving up on an additional child with an increase in income observed today is considered to be caused by a higher desire for an increased quality of life than for additional children [14]. A more in-depth analysis is required between these economic variables and family planning.

According to the results of the 2015 Newlyweds Panel Analysis of Housing Conditions, newlyweds without children showed a large difference regarding income, with $6.0 \%$ of single-income households and 31.5\% of dual-income households having no children [2]. This difference indicates difficulties associated with the newlyweds' working life, responsibilities of raising children, and economic causes. As an increasing number of women enter the social circle, new subsidy fertility policies are required to promote childbirth and reduce the burden of parenting. We also found that a higher level of satisfaction with the environment of the residential area, such as safety, childcare facilities, and the living and transportation infrastructure, have a positive impact on having additional children. A healthy work-life balance between work and childcare is important for the overall fertility rate, as shown in the analysis of the relationship between family characteristics, residential regional environment, and the rate of additional child fertility [16]. 
Table 4. Factors influencing fertility intention of newlyweds for the first child (model 2).

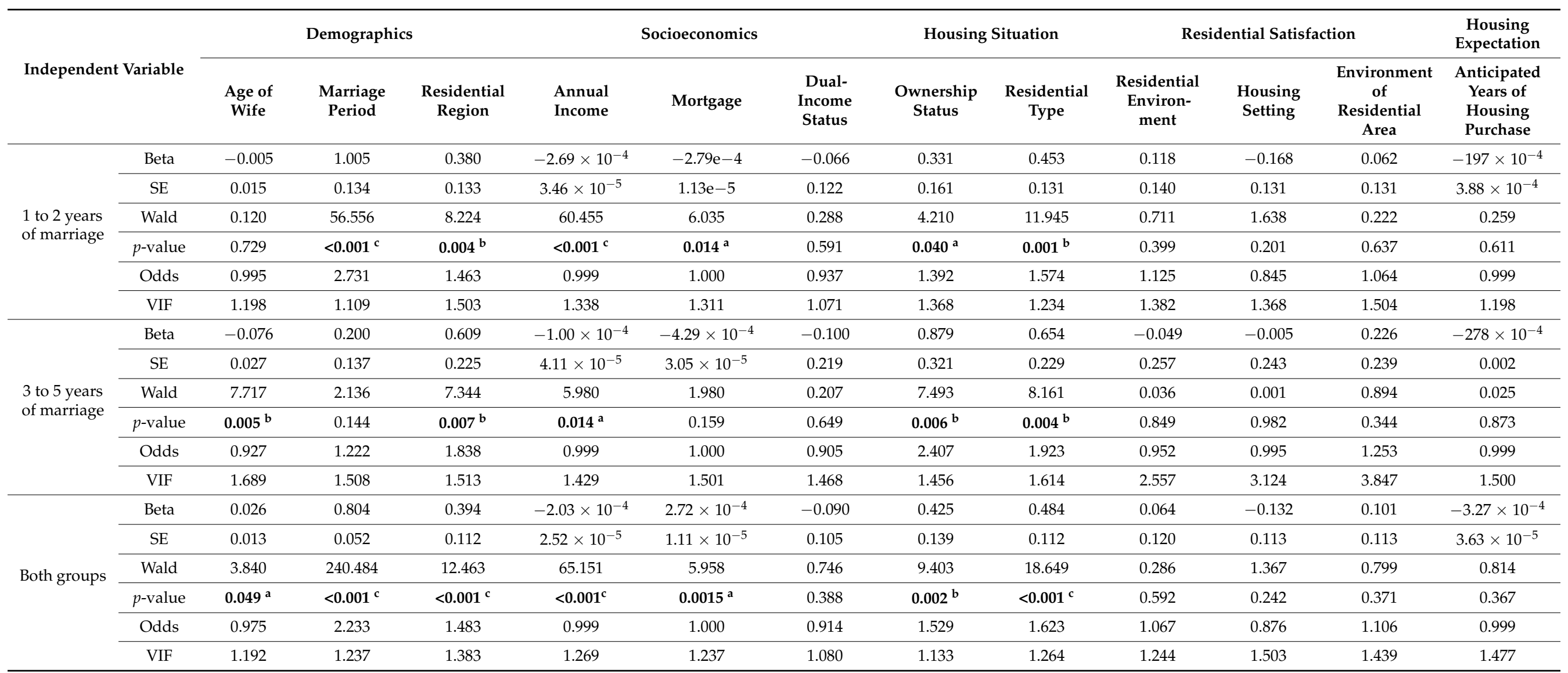

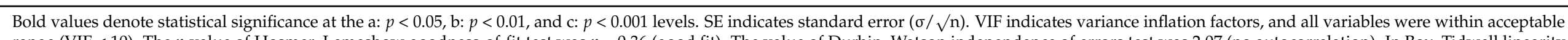

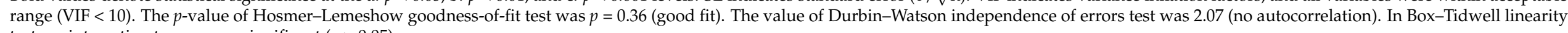
test, no interaction terms were significant $(p>0.05)$. 
Table 5. Factors influencing the fertility intention of newlyweds for additional children (model 3).

\begin{tabular}{|c|c|c|c|c|c|c|c|}
\hline & Independent Variable & Beta & SE & Wald & $p$-Value & Odds Ratio & VIF \\
\hline \multirow[b]{2}{*}{ Demographics } & Age of wife & -0.006 & 0.014 & 0.169 & 0.681 & 0.994 & 1.095 \\
\hline & Marriage period & 0.810 & 0.046 & 306.131 & $<0.001^{\mathrm{c}}$ & 2.247 & 1.130 \\
\hline \multirow{3}{*}{ Socioeconomics } & Annual income & $-1.69 \times 10^{-4}$ & $3.64 \times 10^{-5}$ & 21.650 & $<0.001^{\mathrm{c}}$ & 0.999 & 1.161 \\
\hline & Mortgage & $1.27 \times 10^{-5}$ & $-9.75 \times 10^{-5}$ & 1.698 & 0.193 & 1.000 & 1.117 \\
\hline & Dual-income status & -0.263 & 0.110 & 5.743 & $0.017^{\mathrm{a}}$ & 0.768 & 1.057 \\
\hline \multirow{2}{*}{ Housing situation } & Ownership status & 0.056 & 0.146 & 0.148 & 0.701 & 1.058 & 1.033 \\
\hline & Residential type & 0.067 & 0.121 & 0.306 & 0.580 & 1.070 & 1.140 \\
\hline \multirow{3}{*}{$\begin{array}{l}\text { Residential } \\
\text { satisfaction }\end{array}$} & Residential environment & 0.182 & 0.124 & 2.151 & 0.142 & 1.199 & 1.461 \\
\hline & Housing setting & 0.122 & 0.121 & 1.018 & 0.313 & 1.130 & 1.500 \\
\hline & Environment of residential areas & -0.273 & 0.111 & 6.037 & $0.014^{\mathrm{a}}$ & 0.761 & 1.299 \\
\hline Housing expectation & The anticipated years of housing purchase & -0.001 & 0.001 & 2.109 & 0.146 & 0.999 & 1.175 \\
\hline
\end{tabular}

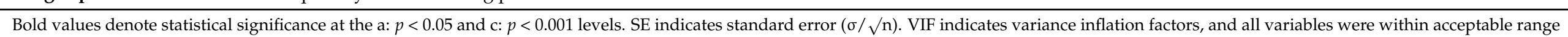

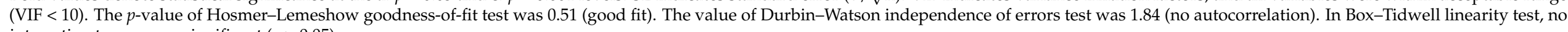
interaction terms were significant $(p>0.05)$. 


\section{Discussion and Conclusions}

This study was conducted to identify the factors affecting the fertility rate of newlyweds in South Korea. On the basis of our quantitative research, we suggest that the following policies should be considered to increase the fertility rate of newlyweds:

First, housing policies promoting economic stability of their first home should be ensured for newlywed couples who plan their first child. For newlywed couples who plan additional children, customized policies are necessary to improve the residential environment, which is directly related to fertility intention. Newlywed households planning to start a family should be targeted by a housing policy that provides economic stability for their initial settlement, and newlyweds who already have children should be targeted by customized policies to improve the residential environment in the area that they live in.

Second, flexible mortgage plans must be implemented for newlyweds in their first 1-2 years of marriage because they generally have few economic assets. It is necessary to lower the interest rate and raise the mortgage limits for long-term rental deposits or home purchases. In particular, increasing the mortgage limit and extending the payment term length is crucial to reduce the burden on metropolitan households [19]. If the government were to loosen the marital income standards for mortgages, more double-income newlywed couples could benefit from mortgages. In order to improve the fertility rate of apartment residents, it is necessary to take measures to ease the interest rate on loans from rent subsidy programs for housing purchases. Furthermore, regarding the period of housing, to induce multiple births through housing stability, as in some Organization for Economic Co-operation and Development (OECD) countries, an institutional mechanism is required to suppress excessive increases in monthly rent.

Third, appropriate residential and economic policies based on income status should be supported. For example, the results showed that the fertility intention of newlyweds in rental households was higher than that in own households, which can be explained by the complex influence of income, the women's educational background, and the residential environment in which children can be raised [20]. Our data show that the income of newlyweds in self-owned households was higher than that of newlyweds in rental households. The higher the income, the higher the women's educational levels and the higher their willingness to engage in social activities, resulting in a lower fertility intention of newlyweds who own their own households. On the contrary, a higher proportion of newlyweds in rental households had a lower income. Since the women's educational level and frequency of social activities were found to be lower than those in self-owned households, the fertility intention was relatively higher [21]. Therefore, personalized support policies based on the income status are needed, such as extended support of childcare expenses for low-income households and a safe environment and daycare facilities for high-income households.

Forth, it is necessary to establish a maternity-friendly urban residential environment since fertility plans of newlyweds are influenced by residential satisfaction. In a previous study, the parenting-friendly urban residential environment was defined as "a convenient and safe environment for individual households to decide whether to have children" [22]. Recently, local governments have made efforts to establish locally differentiated policies by developing "maternity environment indicators" [4].

Comparing South Korea and Japan, the time when the birth rate declined below the replacement fertility level $(\approx 2.1)$ and the time when the low birth rate policy commenced occurred roughly 10 years earlier in Japan. Still, there are many similarities to Korea, such as housing policy trends. Japan's population policy to respond to low birthrates began with the Angel Plan in 1996, but the active policy began after the enactment of the Basic Act on Countermeasures for Small Self-Socialization in 2003. In Japan, the children's allowances are universally paid, adequate housing is provided on the basis of income status, and childcare facilities are installed near the place of residence to create a better environment for raising children. Moreover, the government supports the costs of constructing or remodeling childcare facilities or playgrounds through the multi-dwelling unit certification system [23]. 
On 15 December 2020, Korea announced the "4th Basic Plan for Low Fertility and Aged Society". The government plans to pay the infant allowance and provide a lump sum of 2 million won (approximately EUR 1486, in terms of average basic rate of exchange in 2020) for childbirth to solve the low birthrate problem [24]. However, it is difficult to rebound the fertility rate simply by reducing the burden of childcare because fundamental solutions related to the labor problem are missing. Although the government has set up an additional support policy for parents with children under 12 months of age that pays up to 3 million won (approximately EUR 2229$)$ per month (100\% of normal wages) for a parental leave of 3 months, most of parents are unable to take parental leave due to their working environment. Additionally, the low fertility rate issue is the result of a complex combination of various factors, such as unstable employment, the burden of education costs, and gender discrimination experienced by young people. Labor market gaps, unstable employment problems, and low wages are factors that hamper marriage and childbirth. The gender-discriminatory structure in which women are burdened with parenting and housework also contributes to the low birth rate [13]. It is important not only to raise the fertility rate but to prepare a new vision and adaptative policy for society.

This study has the following limitations. First, since we focused on married couples, the factors affecting the marriage and fertility of unmarried couples were not analyzed. Therefore, follow-up studies are needed on the fundamental factors of unmarried people. Second, the low birthrate problem is a complex result of various factors in addition to demographic, social, and residential environment factors [23]. Therefore, follow-up studies are warranted on socio-structural causes and solutions on various aspects, such as labor, economy, and politics.

We quantitatively confirmed various factors such as demographics, socioeconomics, housing situation, residential environment, and housing expectation that significantly impact the fertility intentions of newlyweds. Housing policies, such as lower interest rates, higher loan limits, extended repayment periods, and eased loan qualifications, could help newlyweds settle in the early stages and increase their fertility intentions. Childcare support policies should be improved, such as the expansion of reliable childcare facilities and the introduction of an equal parental leave system that enables joint parenting of couples. Since the low birthrate problem is the result of complex factors such as population, society, economy, and housing, an integrated policy should be implemented that considers various aspects of the issue, not just one-time support for subsidies. The results of this study are expected to substantially contribute to raising the fertility rate of newlyweds in South Korea by meeting the needs of families that have children and reinforcing housing policies in the future.

Author Contributions: Conceptualization, S.J., M.L., and S.K.; methodology, S.J. and M.L.; validation, S.J. and M.L.; formal analysis, S.J. and M.L.; investigation, S.J. and M.L.; data curation, S.J. and M.L.; original draft preparation, S.J. and M.L.; review and editing, S.J., M.L., and S.K.; supervision, S.K. All authors have read and agreed to the published version of the manuscript.

Funding: This research received no external funding.

Institutional Review Board Statement: Not applicable.

Informed Consent Statement: Not applicable.

Data Availability Statement: Data are publicly and freely available from the Newlyweds Panel Analysis of Housing Conditions released by the Ministry of Land, Infrastructure and Transport (https://mdis.kostat.go.kr).

Acknowledgments: This article was prepared on the basis of the award-winning work of the 2016 Residential Environment Statistical Research Contest using the microdata of the Korea Research Institute for Human Settlement [25].

Conflicts of Interest: The authors declare no conflict of interest. 


\section{References}

1. The Korean Statistical Information Service (KOSIS). The Population Trend Research; KOSIS: Daejeon, Korea, 2019.

2. The Ministry of Land, Infrastructure and Transport. Second Year Newlyweds Panel Analysis Report; The Ministry of Land, Infrastructure and Transport: Sejong City, Korea, 2015.

3. Shin, Y. An Analysis on Determinants of Newlywed's Hosing Tenure Choice. Master's Thesis, Konkuk University, Seoul, Korea, 2016.

4. Lee, S. A Study on the Effects of the Residential Environment one Fertility and Its Political Counterplan; Korea Institute for Health and Social Affairs: Yeongi-gun, Korea, 2013; Volume 183, pp. 1-4.

5. Chun, H. The Political Plan of Housing Support for Dealing with Low Fertility Issues: Special Directions of Urban Policy and Housing Policy in the Low Fertility Times; The Korea Research Institute of Human Settlements: Yeongi-gun, Korea, 2012.

6. Jeong, S. The counterplan of low fertility, what is the problem? Korea J. Popul. Stud. 2015, 38. [CrossRef]

7. Seo, J. Factors Influencing married women's childbearing willingness based on number of children-ever-born. Korea J. Popul. Stud. 2015, 38, 3-6.

8. Jeong, E. A Study on the Factors Related to the Fertility and Pregnancy for the Second Child; Korea Institute for Health and Social Affairs: Yeongi-gun, Korea, 2013; Volume 137, pp. 5-8.

9. Kang, H. A Study on the Influencing Factors on the Subsequent Fertility of Employed Mothers. Ph.D. Thesis, Jung-an Theological Seminary, Seoul, Korea, 2014.

10. Park, T.; Choi, H.; Han, Y. Effect Analysis of Neighborhood Environment on Childbearing-Women's Residential Satisfaction and Childbirth Intention; The Korea Research Institute of Human Settlements: Yeongi-gun, Korea, 2016; Volume 89, pp. 111-130.

11. Lee, S. Paradigm Shifts in Family Policy on Changes in Marriage and Fertility Behavior 2016-44; Korea Institute for Health and Social: Sejong, Korea, 2016.

12. Mulder, C.H.; Billari, F.C. Homeownership regimes and low fertility. Hous. Stud. 2010, 25, 527-541. [CrossRef]

13. Masanja, G.F.; Lwankomezi, E.; Emmanuel, C. The effects of declining fertility on household socioeconomic conditions in Tanzania: A comparative study of urban versus rural areas of Kwimba District, Mwanza Region. Int. J. Popul. Res. 2016, 4716432. [CrossRef]

14. Vignoli, D.; Guetto, R.; Bazzani, G.; Pirani, E.; Minello, A. A reflection on economic uncertainty and fertility in Europe. Genus 2020, 76, 1-27. [CrossRef] [PubMed]

15. Sági, J.; Lentner, C. Certain aspects of family policy incentives for childbearing-A hungarian study with an international outlook. Sustainability 2018, 10, 3976. [CrossRef]

16. Lee, S. The National Fertility and the Welfare Patters of Family Health; Korea Institute for Health and Social Affairs: Yeongi-gun, Korea, 2015; Volume 8, pp. 99-111.

17. Jeong, S. Review of theoretical approach to low fertility. Korea J. Popul. Stud. 2009, 49, 167-176.

18. Lee, S.; Choi, H. Analysis on Association between Housing and Fertility; Korea Institute for Health and Social Affairs: Yeongi-gun, Korea, 2012; Volume 47, pp. 73-89.

19. Byeon, D. Predictors of Fertility-Intention Among the Married Man and Women: Utilization of the Theory of Planned Behavior. Ph.D. Thesis, Konkuk University, Seoul, Korea, 2015.

20. Chun, H.; Kim, Y.; Jeong, H.; Kim, H.; Ha, S.; Kim, J.; Youn, Y.; Oh, M.; Kim, T. Housing and Urban Policy Strategies Responding to Low Fertility; The Korea Research Institute of Human Settlements: Sejong City, Korea, 2012.

21. Noh, S. Predictors of Childbearing Intention and Behavior in Married Women: Longitudinal Analysis of Korean Longitudinal Survey of Women and Families. Ph.D. Thesis, Junganng University, Seoul, Korea, 2015.

22. Moon, S. Measures to Build a Childbirth-Friendly Community Environment; Busan Women's Family Development Institute: Busan, Korea, 2016; pp. 9-29.

23. Lee, S.L.; Lee, J.H. Association between Housing and Fertility among Newly Married Couples; Annual Report 2017; Korea Institute for Health and Social Affairs: Yeongi-gun, Korea, 2017; pp. 192-193.

24. The 4th Basic Plan for Low Fertility and Aged Society; Presidential Committee on Ageing Society and Population Policy: Seoul, Korea, 2020.

25. Jeon, S.; Lee, M. Effect Analysis of Residential Environment on Newly Married Couples' Childbirth Intention, 2016 Residential Environment Sta-tistical Research Contest using the Microdata; Korea Research Institute for Human Settlement: Yeongi-gun, Korea, 2016. 